\title{
(6) OPEN ACCESS \\ Impact of non-menthol flavours in tobacco products on perceptions and use among youth, young adults and adults: a systematic review
}

\author{
Li-Ling Huang, ${ }^{1}$ Hannah M Baker, ${ }^{2}$ Clare Meernik, ${ }^{2}$ Leah M Ranney, ${ }^{1,2}$ \\ Amanda Richardson, ${ }^{1}$ Adam 0 Goldstein ${ }^{1,2}$
}

- Additional material is published online only. To view please visit the journal online (http://dx.doi.org/10.1136/ tobaccocontrol-2016-053196)

${ }^{1}$ Lineberger Comprehensive Cancer Center, University of North Carolina, Chapel Hill, North Carolina, USA ${ }^{2}$ Department of Family Medicine, Tobacco Prevention and Evaluation Program, School of Medicine, University of North Carolina, Chapel Hill, North Carolina, USA

Correspondence to Dr Li-Ling Huang, Lineberger Comprehensive Cancer Center University of North Carolina, Chapel Hill, Chapel Hill, NC 27599, USA;

huang|@email.unc.edu

Received 24 May 2016 Revised 14 October 2016 Accepted 26 October 2016 Published Online First 21 November 2016

CrossMark

To cite: Huang $L-L$,

Baker HM, Meernik C, et al. Tob Control

2017:26:709-719.

\section{ABSTRACT}

Objective This systematic review examines the impact of non-menthol flavours in tobacco products on tobacco use perceptions and behaviours among youth, young adults and adults.

Data sources English-language peer-reviewed publications indexed in 4 databases were searched through April 2016.

Study selection A search strategy was developed related to tobacco products and flavours. Of 1688 articles identified, we excluded articles that were not English-language, were not peer-reviewed, were qualitative, assessed menthol-flavoured tobacco products only and did not contain original data on outcomes that assessed the impact of flavours in tobacco products on perceptions and use behaviour.

Data extraction Outcome measures were identified and tabulated. 2 researchers extracted the data independently and used a validated quality assessment tool to assess study quality.

Data synthesis 40 studies met the inclusion criteria. Data showed that tobacco product packaging with flavour descriptors tended to be rated as more appealing and as less harmful by tobacco users and non-users. Many tobacco product users, especially adolescents, reported experimenting, initiating and continuing to use flavoured products because of the taste and variety of the flavours. Users of many flavoured tobacco products also showed decreased likelihood of intentions to quit compared with non-flavoured tobacco product users.

Conclusions Flavours in most tobacco products appear to play a key role in how users and non-users, especially youth, perceive, initiate, progress and continue using tobacco products. Banning non-menthol flavours from tobacco products may ultimately protect public health by reducing tobacco use, particularly among youth.

\section{INTRODUCTION}

In 2010, WHO Framework Convention on Tobacco Control guidelines recommended restrictions or bans on flavours in tobacco products and recognised that 'masking tobacco smoke harshness with flavours contributes to promoting and sustaining tobacco use' and that 'there is no justification for permitting the use of ingredients, such as flavouring agents, which help make tobacco products attractive'. ${ }^{1}$ Jurisdictions (including cities, states/ provinces and countries) around the world have taken legislative measures to regulate flavours in tobacco products with different levels of restrictions to reduce tobacco product attractiveness, especially among youth. The 2009 US Family Smoking
Prevention and Tobacco Control Act (FSPTCA) banned cigarettes containing non-menthol flavourings, ${ }^{2}$ a step that other global entities, including the European Union (EU), Australia and France, have also taken. Other countries, such as Canada and Brazil, have extended, or are in the process of extending, flavour bans to include other tobacco products and even menthol flavour. ${ }^{3}$

The passage of the FSPTCA was influenced by data showing that candy-flavoured and fruitflavoured cigarettes may be marketed to selectively appeal to and attract younger consumers. ${ }^{4-6}$ An examination of tobacco industry documents outlines perceived benefits of flavoured products to consumers, including pleasing aromas and aftertaste, increased excitement about the flavours and smoking enjoyment and a 'high curiosity to try factor'. Flavouring was determined as one of the key factors underlying the growth in smokeless tobacco sales from 2005 to 2011, accounting for $59.4 \%$ of the total growth in moist snuff sales alone. ${ }^{7}$ Owing to the reported rapid rise of novel tobacco products and the concern over their effects on public health, the US Food and Drug Administration (FDA) finalised a rule in May 2016 to extend its authority over all tobacco products (also known as the 'deeming rule'). ${ }^{8}$ FDA cited the high prevalence of flavoured tobacco use among youth and young adults as a reason for extending their authority over other tobacco products. ${ }^{8}$ However, FDA has not banned flavours in non-cigarette tobacco products in the final deeming rule but intends to issue a proposed product standard for prohibiting flavoured cigars, including cigarillos and little cigars. ${ }^{9}$

Despite recent bans on flavoured cigarettes in some countries, the marketing and sale of flavoured cigarettes still occurs in many countries. Further, the marketing and sale of exempted flavoured non-cigarette tobacco products is still broadly allowed, and the tobacco industry continues to introduce new flavours in non-cigarette products into the market. ${ }^{10}$ The use of flavoured noncigarette tobacco products remains high. For example, in 2014 , $12 \%$ of US middle and high school students used flavoured tobacco products in the past 30 days, ${ }^{11}$ and a 2012 study found that $19 \%$ of US young adults reported past 30-day use of flavoured tobacco products. ${ }^{12}$ The prevalence of flavoured tobacco product use in the last 30 days among Canadian students in grades 9 through 12 is also high, at $10 \%$ in $2013 . .^{13}$

Understanding the impact of flavouring on tobacco use is a research priority outlined by FDA 
Figure 1 PRISMA flow diagram of article identification, screening and selection. * ${ }^{*}$ Checking reference lists of included articles.

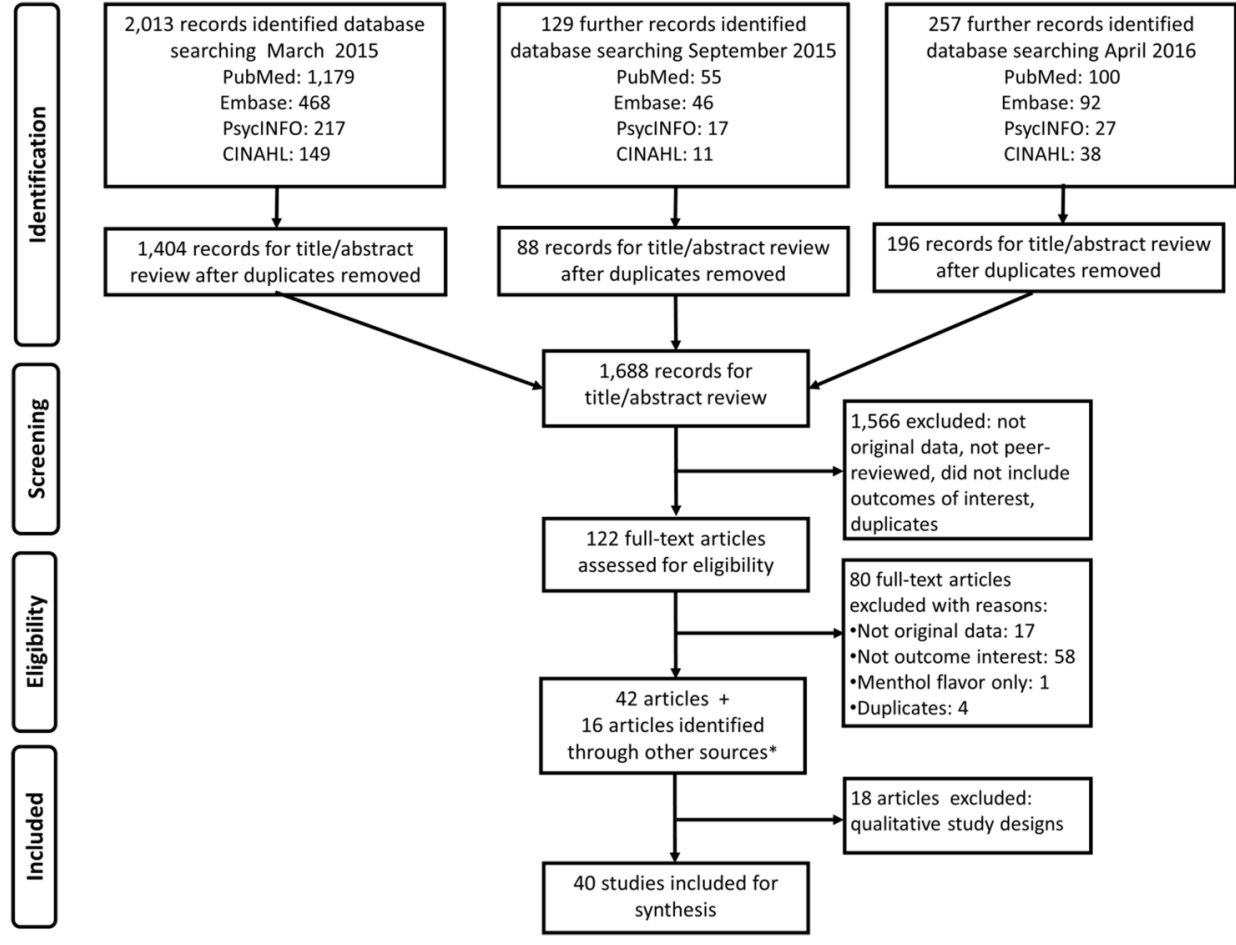

Center for Tobacco Products, ${ }^{14}$ and it is an area of interest for tobacco researchers and government bodies worldwide. ${ }^{15}$ While FDA and its affiliated Tobacco Products Scientific Advisory Committee have investigated the effect of menthol flavouring on public health, ${ }^{16}{ }^{17}$ more limited work has investigated the impact of non-menthol flavouring on youth and adult perceptions, initiation, use and cessation of diverse tobacco products.

A recent systematic review examined the use of and attitudes towards non-menthol flavoured tobacco products, ${ }^{18}$ but its scope was limited to US studies only, and only studies prior to September 2013 were included. ${ }^{18}$ While this review did examine the prevalence of flavoured tobacco use and the relationships between flavoured tobacco use and age, it did not critically examine the role that non-menthol flavouring plays in tobacco use behaviours, such as initiation and cessation, and whether the flavouring in tobacco products specifically affects these relationships. Given the rapid pace at which the marketplace and research on flavoured tobacco products are evolving, and the interest of the topic to domestic and international policymakers, we conducted a systematic review of articles published through April 2016 to investigate the role of non-menthol flavoured tobacco products in attitudes, perceptions, intentions, use and cessation of tobacco products in the USA and globally.

\section{METHODS}

\section{Eligibility criteria}

Eligibility criteria of participants included populations of any age, race, sex, ethnicity or country. We excluded the following types of articles: those that were not English-language; were not peer-reviewed; did not contain original data about flavoured tobacco products; did not address the impact of flavours on tobacco product perceptions and use behaviours; were related to smoking marijuana and limited findings to menthol flavoured tobacco products only. For this paper, we excluded articles that used qualitative study designs.

\section{Type of outcome measures and intervention}

Our outcome measures included reasons for using flavoured tobacco products; perceptions about product taste, appeal and health risks; expectancies and beliefs; intention to try; intention to quit; use behaviours, including experimentation, initiation, preference and progression to regular use, dual or poly tobacco use, and cessation.

\section{Data sources and study selection}

One author (HMB) conducted searches of PubMed, Embase, PsycINFO and CINAHL during March 2015. A general search strategy was developed using Boolean language to connect variants of words related to tobacco products and use and flavour for PubMed, ${ }^{\mathrm{i}}$ which was translated to match the search string requirements for other databases. To supplement the database search, two authors (CM and HMB) conducted a manual search of the reference lists in each of the included articles. In September 2015, authors conducted a second search using the same search strings and databases to include articles published and indexed after the initial search. A total of 2013 articles resulted from searching the 4 databases during the initial search products[mesh] OR smoking[mesh]) AND flavoring agents[mesh] OR (((smoke OR smoker OR smokers OR smokes OR smokings OR smoking OR cigarette OR cigarettes OR cigar OR cigars OR cigarillos OR cigarillo OR hookahs OR hookah OR waterpipe OR waterpipes OR narghile OR narghiles OR argila OR argiles OR tobacco OR tobaccos OR cigar* OR $O R$ vape $O R$ vapor $O R$ vapour $O R$ vapours $O R$ vapors $O R$ vapor $O R$ vapors $\mathrm{OR}$ vaping $\mathrm{OR}$ snus $\mathrm{OR}$ pipe $\mathrm{OR}$ pipes $\mathrm{OR}$ "e-cigarette" $\mathrm{OR}$ "e-cigarettes" OR bidi OR bidis OR kretek OR kreteks OR chewing tobacco OR snuff OR shisha OR "water pipe" OR "water pipes" OR goza OR narkeela OR "hubble bubble" OR hukkah OR hukkas OR hukka OR argileh) AND (flavor OR flavor* OR flavour OR flavour* OR flavors OR flavours OR flavoring OR flavouring OR flavorings OR flavourings OR flavoured OR flavoured OR flavoring OR flavorings OR flavouring OR flavourings OR flavouring OR flavoring OR flavourants OR flavorants)) OR (kretek OR kreteks OR bidi OR bidis)).
${ }^{\mathrm{i}}$ Final PubMed search string: (electronic cigarettes[mesh] OR tobacco smoke* OR tobacco" OR ends OR "electronic nicotine delivery system*” 
(March 2015) (figure 1). After authors removed duplicates, 1404 articles remained for title and abstract review. The second search (September 2015) identified 88 additional articles for title/abstract review after de-duplication. Owing to the rapid pace of research on flavoured tobacco products, a third search was conducted in April 2016. This search identified 196 articles for title/abstract review after removing duplicates. Two authors (CM and HMB) reviewed the full text of articles eligible for full-text screening. A third author (L-LH) resolved any discrepancies on inclusion decisions. In total, 122 full-text articles from the databases were assessed for eligibility, along with an additional 16 articles using the same eligibility criteria through the manual search of references. Eighty articles were excluded because they did not include original data $(n=17)$, did not have data on the specified outcomes $(n=58)$, were only on menthol $(n=1)$ or were duplicates to the previous searches $(n=4)$. Eighteen articles with a qualitative study design were further excluded from analysis. A total of 40 articles were included in the final analysis. The study selection processes, including reasons for exclusion at the full-text review phase, are illustrated in figure 1.

\section{Data extraction and synthesis}

Two authors (CM and L-LH) independently extracted data using a pilot-tested data extraction sheet, which assessed study aim, type of flavoured tobacco product, characteristics of study populations and study design, and main results and findings related to the impact of flavours in tobacco products. We used a validated quality assessment tool (QATSDD) to examine the quality of quantitative studies with a diverse range of research designs. ${ }^{19}$ Studies were scored on a 4-point scale from 0 (did not address criteria at all) to 4 (completely addressed criteria), with specified guidance to inform scorers based on the level of detail provided by study authors. ${ }^{19}$ Specific scores were not used for inclusion/exclusion or used in any analysis. Rather, the tool was used to provide a valuable overall assessment of the general quality of included studies from which our conclusions are based. To ensure agreement in data extraction and quality assessment, two authors (CM and L-LH) reviewed and extracted a sample of the same five articles and resolved discrepancies through an iterative approach of discussion. We created evidence tables using pertinent information extracted from each study, and we grouped the results by outcome measures. Owing to the heterogeneity in outcomes across studies, a meta-analysis was not conducted.

\section{RESULTS}

Over half of the 40 included studies were conducted in the USA (table 1), and most studies (90\%) were published between 2010 and 2016. The majority of the studies used cross-sectional data, with one study using a longitudinal design. ${ }^{21}$ Table 1 lists product types examined and relevant outcomes for included studies. Descriptions of study design and main findings are provided in table 2 (more detailed results of included studies are in the online supplementary table).

\section{Taste, appeal, risk perceptions}

Eleven studies examined taste, appeal and perceived risk for flavoured tobacco products. Four studies with similar study designs assessed the impact of cigarette packaging descriptors with and without flavours among girls and young women in Brazil, ${ }^{46}$ Canada, ${ }^{40}$ the UK ${ }^{42}$ and the USA. ${ }^{41}$ Results indicated that removing flavour descriptors from packs significantly reduced measures of taste ${ }^{40-42} 46$ and appeal. ${ }^{40} 4246$ Further,
Table 1 Product types and outcome measures of included studies

\begin{tabular}{|c|c|c|}
\hline Sample characteristics & N & $\begin{array}{l}\text { US* studies } \\
(n=23)\end{array}$ \\
\hline
\end{tabular}

\begin{tabular}{|c|c|c|c|}
\hline \multicolumn{4}{|l|}{ Product type } \\
\hline E-cigarette & 17 & 10 & 7 \\
\hline Cigarette & 10 & 4 & 6 \\
\hline Little cigar, cigarillo, cigar & 4 & 2 & 2 \\
\hline Hookah & 3 & 2 & 1 \\
\hline Various tobacco products & 3 & 2 & 1 \\
\hline Smokeless tobacco & 2 & 2 & 0 \\
\hline Bidi & 1 & 1 & 0 \\
\hline \multicolumn{4}{|l|}{ Outcome measures $¥$} \\
\hline Taste, appeal, risk perceptions & 11 & 4 & 7 \\
\hline Preference & 10 & 4 & 6 \\
\hline Expectancies and beliefs & 6 & 3 & 3 \\
\hline Reasons for use & 7 & 5 & 2 \\
\hline Intention to try, initiation & 12 & 7 & 5 \\
\hline Progression to regular use & 2 & 1 & 1 \\
\hline Dual/poly use & 3 & 2 & 1 \\
\hline Quit intention and quitting behaviour & 4 & 2 & 2 \\
\hline
\end{tabular}

two of the studies found that packs with flavour descriptors were more likely to be rated as lower health risk than packs without descriptors, ${ }^{42}$ and young girls were significantly more likely to rate packs with flavour descriptors as less harmful than young women. ${ }^{46}$ Similarly, a smokeless tobacco packaging study of 1000 participants in the USA found that among those who reported a difference between packaging elements on their product opinions, more youth and young adults perceived the pack with flavour descriptors as having better taste and as more appealing compared with the pack without flavour descriptors. ${ }^{53}$ Young adults were also more likely than older adults to report that packs without flavour descriptors would deliver more dangerous chemicals than those with flavour descriptors. ${ }^{53}$ A longitudinal study with large numbers of participants from the USA, Mexico and Australia examined cigarette brands with flavour capsules and found that, compared with adult smokers of regular non-flavoured cigarettes, adults who preferred brands with flavour capsules viewed their variety of cigarettes as having better taste, as more appealing and less harmful (except Australian smokers) than other brand varieties. ${ }^{21}$ A UK study of 1205 adolescents assessed the impact of electronic cigarette (e-cigarette) flavour descriptors on perceptions of product harm and also found perceptions of harm differed depending on the flavours. ${ }^{28}$ Tobacco flavoured e-cigarettes were perceived as being more harmful, while cherry and candy floss flavours were perceived as less harmful. ${ }^{28}$ An online study conducted among 915 Canadians aged 16 years and older found that flavours accounted for 36\% of consumers' overall perceptions of reduced harm about e-cigarettes, as equally influential as health warnings (35\%), while other product attributes such as nicotine content and price were less influential in perceived reduced harm. ${ }^{24}$ Younger smokers and non-smokers particularly perceived cherry-flavoured or coffee-flavoured e-cigarettes as less harmful, while older smokers indicated tobacco flavour as being less harmful. ${ }^{24}$ In a UK study of 471 e-cigarette and cigarette non-users, aged 11-16 years, flavoured e-cigarette advertisements were more appealing than non-flavoured e-cigarette 


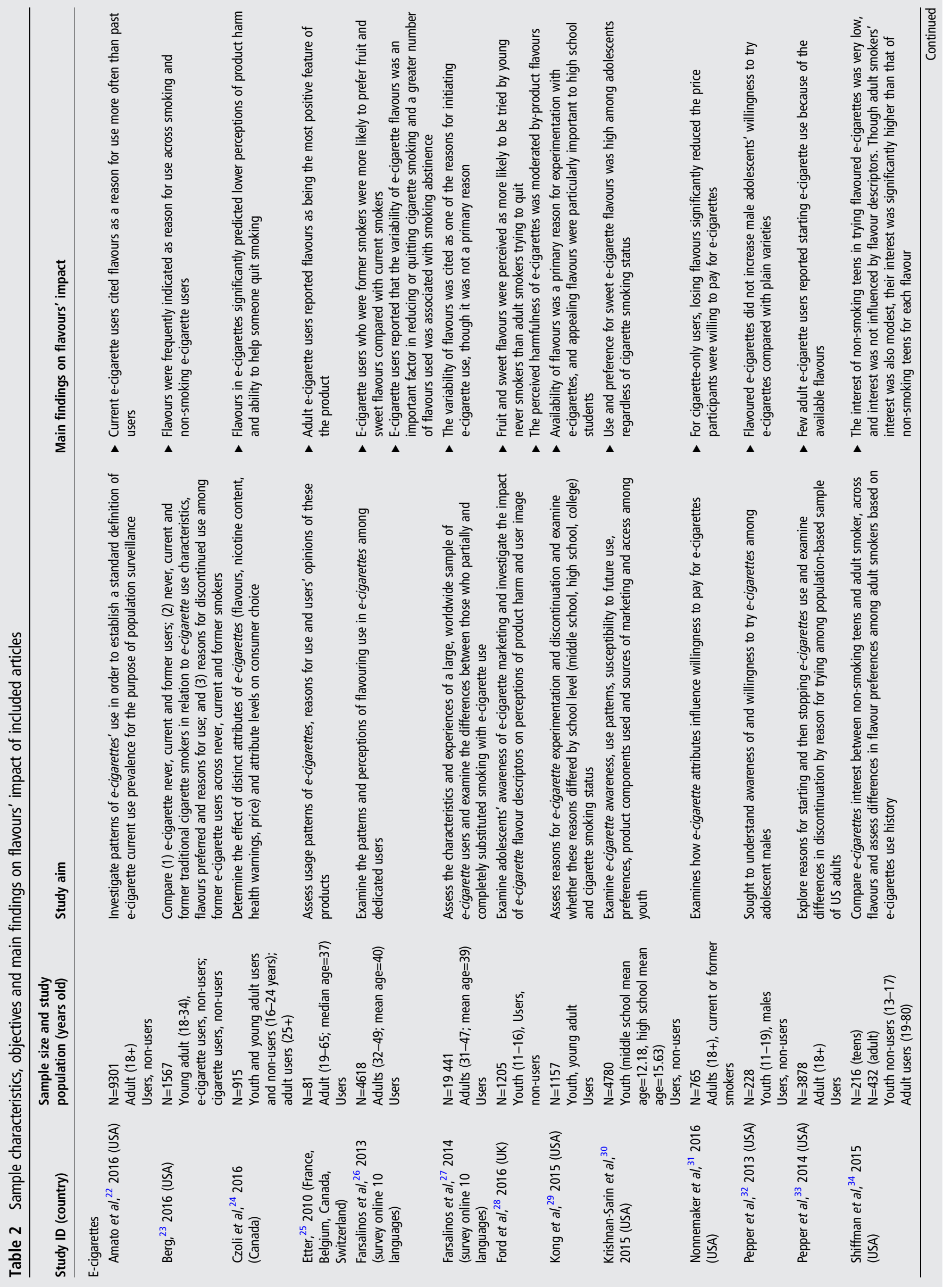









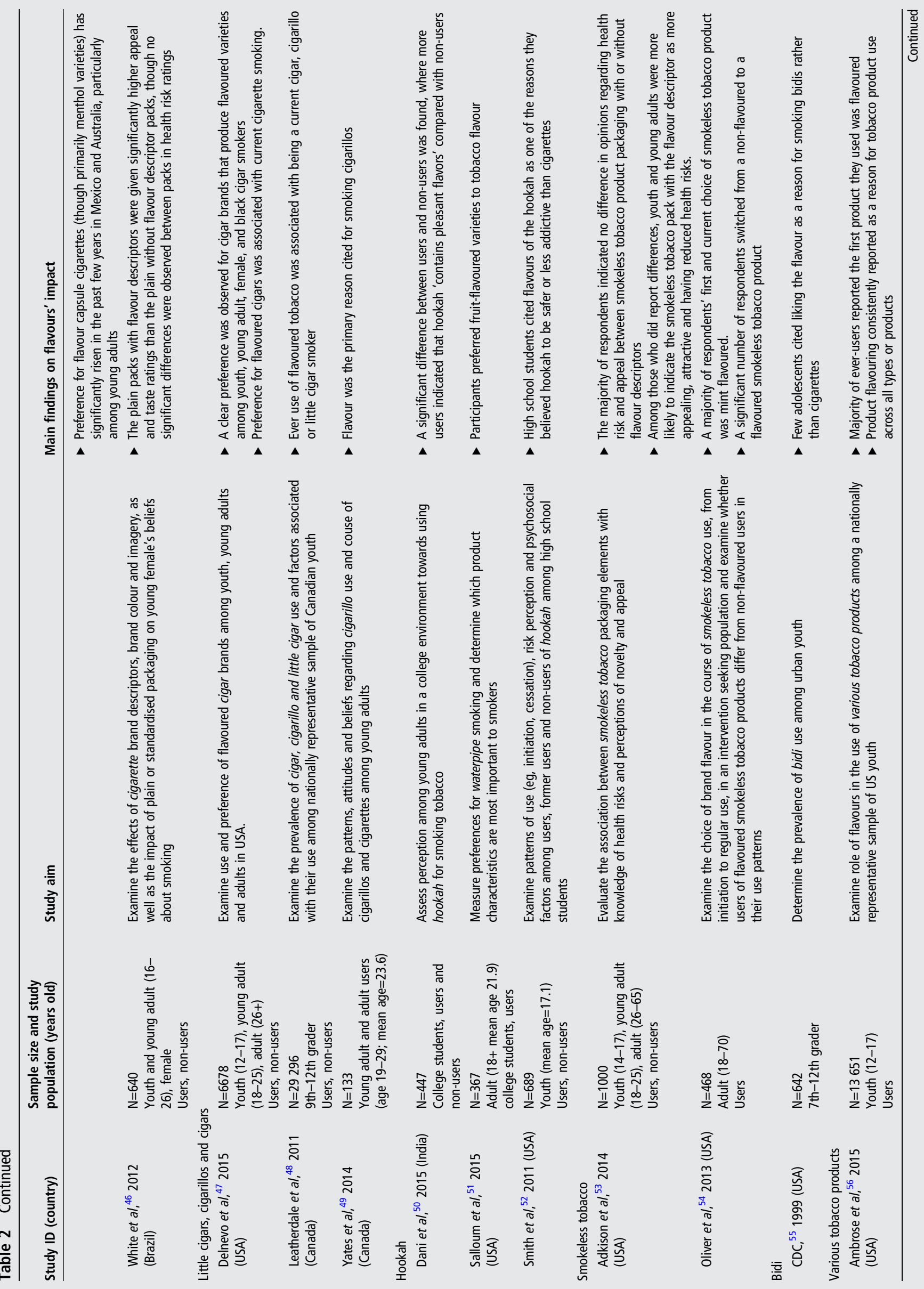


advertisements. ${ }^{37}$ A study of 689 US adolescents cited flavours as one of the reasons why they perceived hookah to be safer or less addictive than cigarettes. ${ }^{52}$ However, a small US study of 20 college smokers did not detect an appreciable difference in harshness or irritation between flavoured and non-flavoured cigarettes. $^{45}$

\section{Preference}

Ten studies examined preference for flavoured tobacco products. One US study of 4780 middle and high school students found that preference for sweet e-cigarette flavours was high, with most lifetime and current e-cigarette users reporting they preferred sweet flavours compared with menthol and tobacco flavours when they smoked e-cigarettes. ${ }^{30}$ A UK study of 1205 adolescents also found that fruit, sweet and coffee flavours in ecigarettes were perceived as more likely to be tried by young never smokers compared with tobacco flavour, and these flavours were perceived as more likely to be used or tried by young never smokers than adult smokers trying to quit smoking. ${ }^{28}$ Three studies among adult e-cigarette users reported that the variety of flavour choices was rated as important by the majority of users (85.4\%) and influenced device choice; ${ }^{20}$ most users $(72 \%)$ preferred vaping non-traditional flavours such as fruity and candy/nuts to traditional flavours (ie, menthol or tobacco) $;^{36}$ and former cigarette smokers were more likely to use fruit and sweet flavours. ${ }^{26}$ Similarly, a US study of 6678 participants reported a clear preference among youth, young adults, female and black cigar smokers for cigar brands that produce flavoured varieties. ${ }^{47}$ Many current adult cigarette smokers (33\%) in 27 EU countries, particularly female smokers, reported specific sweet, menthol or fruity flavours as important in their cigarette brand preference. ${ }^{38}$ Preference for flavour capsule cigarette brands has significantly risen in recent years in Mexico and Australia, particularly among young adults (though the majority of the flavour capsule varieties reported refer to menthol). ${ }^{21}$ But a US study of 20 college smokers did not find a relationship between preference and whether the brand of cigarette was flavoured or non-flavoured. ${ }^{45}$ An online study of 367 US college hookah users found that participants preferred fruitflavoured varieties to tobacco flavour. ${ }^{51}$ Further, flavour accounted for almost two-thirds of the hookah use decision, compared with price $(22 \%)$ and nicotine content $(13 \%) .{ }^{51}$

\section{Expectancies and beliefs}

Six studies examined expectancies and beliefs of flavoured tobacco products that influence consumers' decisions. An online study conducted among 915 Canadians found that flavours in e-cigarettes had a moderate influence $(25 \%)$ on judgements of product efficacy in quitting smoking compared with other product attributes such as nicotine content (10\%), price $(26 \%)$ and health warnings (39\%). ${ }^{24}$ Another online US study of 765 adult smokers that estimated the value smokers placed on attributes of e-cigarettes found that removing the attribute 'coming in flavours' significantly reduced the price smokers were willing to pay among e-cigarette-only users. ${ }^{31}$ Among 424 US college students, Camel Exotics (flavoured cigarettes) produced greater positive expectancies than did Camel Lights (non-flavoured cigarettes), with the strongest difference among susceptible/ experimenters. $^{39}$ In addition, participants rated Camel Lights more negatively than Camel Exotics; this relationship held true across non-smokers, susceptible/experimenters and regular smokers. A cigarette packaging study among 253 high school students in the USA found that flavour descriptors led to more positive beliefs about the hedonic qualities (eg, enjoyable, 
relaxing, good tasting) of brands than the traditional descriptors, although this interaction was only significant among high sensation seekers. ${ }^{44} \mathrm{~A}$ study of 81 adult e-cigarette users in four countries found that the most frequently cited positive feature of e-cigarettes was their taste and variety of flavours $(18 \%$ of total open-ended comments). ${ }^{25} \mathrm{~A}$ study of 447 young adults in India that assessed perception of hookah use, $36.8 \%$ of hookah users indicated that hookah 'contains pleasant flavours', which was significantly higher than non-users $(24.6 \%) .^{50}$

\section{Reasons for use}

Seven studies addressed reasons for using flavoured tobacco products. In a US study of 13651 adolescents, product flavouring was consistently reported as the most common reason for use across all product types, including e-cigarettes $(81.5 \%)$, hookah (78\%), cigars (73.8\%), smokeless tobacco (69\%) and snus pouches $(67.2 \%) .{ }^{56}$ An online study of 1567 adults found that a majority of e-cigarette users $(60 \%)$ and one-third of non-users reported reasons or interest for using e-cigarettes because 'they come in appealing flavors' and 'I like experimenting with various flavors.'. ${ }^{23}$ This study also found that flavours were a common reason for discontinued use of e-cigarettes among former e-cigarette users because they 'don't like the flavor(s)'. ${ }^{23}$ In an online study of 1095 Canadians, 'they taste good' was a more common reason for using e-cigarettes cited by younger non-smokers (32.3\%) and smokers (18.4\%) than by older smokers (6.5\%). ${ }^{35}$ In a US study of 9301 adults, $55.5 \%$ of daily e-cigarette users, $50.4 \%$ of infrequent e-cigarette users (15 days in past 30 days) and $41.9 \%$ of intermediate e-cigarette users (6-29 days in past 30 days) reported the availability of flavours (not including menthol) as a reason to use e-cigarettes, while cutting down on other tobacco products was the most common reason cited for e-cigarette use among daily $(91 \%)$ and intermediate $(84.6 \%)$ users. $^{22}$ In an online US study of 3878 adults, $8 \%$ of e-cigarette users reported flavours as a reason for first trying e-cigarettes compared with $53 \%$ of respondents reporting first using e-cigarettes out of curiosity, and 30\% reporting first using them because they wanted to quit or reduce smoking. ${ }^{33}$ In an urban sample of 133 Canadian young adults, the primary reason reported for smoking cigarillos was because of the flavour (56\%). ${ }^{49}$ Among a convenience sample of 642 youth in Massachusetts, only 1\% reported using bidis instead of cigarettes because of the flavour, but $23 \%$ said bidis tasted better than cigarettes. ${ }^{55}$

\section{Intention to try/initiation}

Twelve studies assessed intention to try or initiation of flavoured tobacco products. In a US study of 13651 adolescents, the majority of ever users $(80.8 \%)$ reported that the first product they had used was flavoured, including hookah (88.7\%), e-cigarettes $(81.0 \%)$, snus pouches $(81.2 \%)$, smokeless tobacco excluding snus (68.9\%), any cigar type (65.4\%) and cigarettes $(50.1 \%) .^{56}$ The majority of past 30 -day users $(79.8 \%)$ also reported that the products used were flavoured. ${ }^{56}$ One US study of 468 adult users reported a majority (60\%) of participants' first smokeless tobacco product used was mint flavoured. ${ }^{54}$ A study in the EU found that though few ever adult cigarette smokers $(1.4 \%)$ reported specific flavours as being important in their initial smoking, flavours were significantly associated with initial smoking in younger smokers aged $15-24 .{ }^{38}$ Among US adolescents and young adults, flavoured cigarette brands led to higher trial intentions compared with non-flavoured cigarette brands in two different studies. ${ }^{39}{ }^{44}$ In an online study of 915 Canadians aged 16 years and older, flavour accounted for $24 \%$ of consumers' intentions to try e-cigarettes, showing a moderate influence compared with other product attributes. ${ }^{24}$ Younger smokers and non-smokers were particularly interested in trying cherry-flavoured e-cigarettes, while older smokers indicated greater interest in trying tobacco flavour. ${ }^{24} \mathrm{~A}$ US study of 1157 adolescent and young adult ever e-cigarette users found that the availability of flavours was a primary reason for experimentation with the product, particularly among high school students compared with college students. ${ }^{29}$ An online study of 1095 Canadians showed that younger non-smokers were less likely to try a flavoured e-cigarette than younger smokers and older smokers. ${ }^{35}$ In a UK study of 471 e-cigarette and cigarette non-users aged 11-16 years, flavoured e-cigarette advertisements elicited greater interest in buying and trying e-cigarettes than non-flavoured e-cigarette advertisements, but the appeal of using e-cigarettes was low for both sets of advertisements. ${ }^{37} \mathrm{~A}$ US study of 228 male adolescents found that their willingness to try e-cigarettes compared with plain varieties did not differ based on flavour status, although virtually none of the males $(<1 \%)$ had tried e-cigarettes previously. ${ }^{32}$ An online European study, financially underwritten by an e-cigarette users advocacy group, reported that initiating e-cigarette use to enjoy the variability of flavours was ranked as a 3 on a 5 -point scale from 1 (not important) to 5 (most important). ${ }^{27}$ A US online study, financially supported by a company that markets e-cigarettes, reported that non-smoking teens' interest in trying e-cigarettes did not vary by flavour, but adult smokers' interest did. ${ }^{34}$

\section{Progression to regular use}

Two studies examined the impact of flavoured tobacco on the progression from tobacco initiation to regular use of flavoured products. ${ }^{48} 54$ A US study that used data from five separate studies of adult smokeless tobacco users at various stages of reducing or quitting tobacco found that among smokeless tobacco users who started using mint-flavoured products, $64.4 \%$ reported current use of flavoured products, whereas $48.7 \%$ of those who started using non-flavoured products continued to use non-mint-flavoured products. ${ }^{54} \mathrm{~A}$ nationally representative sample of 29296 high school students from the Canadian Youth Smoking Survey reported a strong association between flavoured tobacco use and being a current cigar, cigarillo or little cigar smoker. ${ }^{48}$ Respondents who reported ever using flavoured tobacco were more likely to currently use cigars, cigarillos or little cigars compared with respondents who had never used flavoured tobacco products. ${ }^{48}$ It should be noted that the two studies used cross-sectional data to examine progression to regular use.

\section{Dual/poly use}

Three studies assessed the role of flavours in dual or poly use of tobacco products. One survey among 24658 middle and high school students in the USA assessed the association between types of use (singular tobacco product vs multiple tobacco products) and found that among current cigarette smokers, the use of flavoured products was significantly associated with dual and poly tobacco use. ${ }^{58}$ Another study found that cigar brands offering flavoured varieties were preferred more by cigar smokers who were also current cigarette smokers. ${ }^{47} \mathrm{~A}$ Canadian study of 17396 young never smokers found that those who had ever tried or tried a flavoured tobacco product in the past 30 days had significantly higher odds of being susceptible to cigarette smoking. ${ }^{59}$ 


\section{Quit intention and quitting behaviour}

Four studies assessed flavoured tobacco use and intention to quit. A study of 18866 US middle and high school students found that flavoured cigar (59.7\%) and cigarette (49.3\%) users had a higher prevalence of not thinking about quitting tobacco than non-flavoured cigar (18.4\%) and cigarette $(9.8 \%)$ users. $^{57}$ Similarly, a study in Poland of 2254 adult users reported that females who smoked flavoured cigarettes were less likely to intend to quit than females who smoked non-flavoured cigarettes. ${ }^{43}$ US adult e-cigarette users who reported vaping nontobacco and non-menthol flavours were more likely to have quit smoking than e-cigarette users who vaped traditional flavours. ${ }^{36}$ One study of adult e-cigarette users, financially underwritten by an e-cigarette user advocacy group, reported that the variability of e-cigarette flavours was an important factor in reducing or quitting smoking and a greater number of flavours regularly used was associated with smoking abstinence among dedicated long-term e-cigarette users. ${ }^{26}$

\section{Risk of bias assessment}

Most studies were rated highly in terms of having explicit aims and objectives, description of research setting and fit between stated research question and method of data collection (see QATSDD scores in online supplementary table). However, a majority of studies did not report an explicit theoretical framework, evidence of sample size consideration and statistical assessment of reliability and validity of measurement tools. Several studies failed to adequately address fit between stated research question and method of data collection (scored at 1 or below). ${ }^{26} 3454$ It is important to note that studies may have received a low score simply because a certain criteria was not described in detail in the manuscript, even though the study authors may have considered it (eg, power calculations for sample size consideration often not reported due to word count constraints). Three studies were financially supported by e-cigarette companies or advocacy groups of e-cigarette users. $^{26} 2734$

\section{DISCUSSION}

This systematic review highlights and extends in important ways what policymakers and public health practitioners strongly suspect: flavours play a key role in influencing perceptions and multiple tobacco use patterns about most tobacco products, particularly for adolescents. Flavours in tobacco products seem to have a universal and rather strong appeal to youth and young adults interested in initiating tobacco use or experimenting with different products due to the variety and availability of flavours, ${ }^{24} 293746475356$ are reported as a reason for using most tobacco products, 22233349515556 and appear to play a more important role in the use of e-cigarettes, hookah, little cigars and cigarillos among younger people. ${ }^{48} 4956$ The availability of non-menthol flavoured tobacco products and their appeal to adolescents have the potential to undermine progress gained on reducing tobacco use. ${ }^{8}$ Flavoured tobacco products were perceived as having better taste and were more appealing by users and non-users, especially among younger age groups. $^{21} 40-424653$ Flavoured tobacco products were also perceived as less risky or harmful, and these perceptions potentially interact with age, with younger participants appearing more likely to believe that flavoured products were less harmful compared with non-flavoured products. ${ }^{21} \quad 24 \quad 28 \quad 42 \quad 53$ Tobacco product users and non-users showed a clear preference for sweet, fruit-flavoured varieties over traditional tobacco flavours, ${ }^{20} 213036384751$ and flavours give tobacco products higher positive expectancies and beliefs about hedonic qualities, product features and values that may influence consumers' decisions more than non-flavoured tobacco products. ${ }^{24} 2531394450$ Not surprisingly, given the strong impact of flavours in perceptions of tobacco products, flavours were associated with progression to regular use and dual and poly use of tobacco products. Tobacco users tended to switch to flavoured products and maintain multiple flavoured products. ${ }^{47} 48545859$ Finally, results from this review showed that the use of flavoured tobacco products, such as cigarettes and cigars, may be associated with lower quit intentions. ${ }^{43}{ }^{57}$ However, two ecigarette studies, one funded by a user advocacy group, found that flavours in e-cigarettes may help adult e-cigarette users in quitting cigarette smoking. ${ }^{26} 36$

Our systematic review significantly expands on a recent systematic review by Feirman et $a l^{18}$ of US studies published through 2013. Our review includes articles that critically summarised data for the first time on the role of flavours in tobacco use perceptions as well as tobacco use behaviours. We specifically examined flavours as being related to taste, appeal, risk perceptions, preference, reasons for use, intention to try, initiation, progression to regular use, dual/ploy use, quit intention and quitting behaviour. Our review also includes 17 non-US studies and 26 new studies published between 2014 and 2016 alone. While there did not appear to be any appreciable difference between the results of US versus non-US studies, it is important to note that most of the non-US studies were conducted in highly developed countries with moderate to strong tobacco regulatory frameworks, such as Canada and the UK.

The relevance of this new systematic review on public policy in the USA and internationally is significant and immediate. First, as the majority of countries have no ban on any flavoured tobacco product, results from this systematic review support the rationale for global regulations on most non-menthol flavoured tobacco products in order to positively impact public health outcomes related to reduced tobacco use. Second, it addresses the FDA's need for data on the role of certain flavoured products in supporting reduction in or abstinence from the use of combustible tobacco products, as well as data on the role of flavoured products in youth initiation and use, as stated in the final deeming rule. Third, this research may help inform countries, such as Brazil, that have banned all tobacco product flavours but face litigation from the tobacco industry. Fourth, it may strengthen efforts of local jurisdictions that have enacted more comprehensive bans on flavoured tobacco products, such as New York City; such bans led to significant reductions in ever use of flavoured tobacco products, from $20 \%$ in 2010 to $16 \%$ in $2013 .{ }^{60}$

Finally, this review may help some countries in strengthening their existing regulations. For instance, the 2010 Canadian Bill C-32, the Cracking Down on Tobacco Marketing Aimed Youth Act, prohibited the sale of all flavoured cigarettes, little cigars and cigarillos, and blunt wraps that weighed $<1.4 \mathrm{~g}$, with an exemption for menthol flavouring. ${ }^{61}$ The prevalence of flavoured tobacco product use among Canadian high school students remained high even after the enactment of this legislation, in part because the tobacco industry reformulated flavoured cigarillos to circumvent the bill (eg, increased the product's weight to more than $1.4 \mathrm{~g}$ ). ${ }^{61}$ Bill C-32 also exempted many categories of tobacco products from regulation (eg, pipe tobacco, smokeless tobacco and cigars). ${ }^{61}$ In 2015, two Canadian provinces extended existing flavour bans on the sale of flavoured tobacco products to include those with menthol 
flavours, but with exemptions for pipe tobacco and some cigars. ${ }^{62}$ This review can be helpful for jurisdictions in formulating more comprehensive and effective bans.

Our review has several limitations. This review did not include grey literature or non-English language articles, leading to the possibility that some relevant results could be missed. The inclusion of grey literature may have expanded the scope of the results and provided additional evidence that has not yet been published. While we assessed the risk of bias in individual studies using a validated tool, we did not set minimum threshold for study quality a priori, and we included several e-cigarette industry or advocacy user funded studies. ${ }^{26} 27{ }^{34}$ Caution should exist in extrapolating results from studies that scored lower in study quality. There also appeared to be a lack of homogeneity in the measures used in each study. Measures of perceptions and use behaviours varied across studies, and established reliability and validity measures are lacking. Invalidated measures may fail to adequately assess what needs to be measured and/or bias results.

Future research may elucidate specific mechanisms underlying the role of flavours in tobacco use perceptions and behaviours; many studies included in this review were not designed to assess flavours as the major predictor variable (table 2). This resulted in some studies lacking power to detect differences in measures between flavoured and non-flavoured conditions (see online supplementary table), thus causing our systematic review to likely underestimate the findings of flavours' impact due to nonsignificant results. The majority of studies used cross-sectional data and did not assess the impact of flavours on behavioural outcomes, such as continued use and abstinence; longitudinal research could examine changes over time in use patterns of tobacco products. Future research is also needed in countries that are not represented in this review, including those with weak tobacco regulatory frameworks, to fill the knowledge gap regarding the role of tobacco flavours in other populations and cultures, as products may differ greatly across countries because of sociocultural difference (eg, smokeless tobacco in the USA is a different product than it is Southeast Asia). As the number of studies examining e-cigarettes and cigarettes included in this review far outweighed the number of studies examining other tobacco products, research examining different products and in different countries may help to elucidate the role that flavour plays in each identified behavioural outcome. Finally, our review did not examine the impact of menthol flavours on outcomes. A previous report of the Tobacco Product Scientific Advisory Committee found sufficient evidence that menthol flavourings in cigarettes increased experimentation and regular smoking and decreased the likelihood of smoking cessation compared with non-menthol cigarettes ${ }^{17}$ findings similar to that of our review on non-menthol flavourings. Future reviews should examine the literature on menthol flavourings to determine if the impact of menthol flavouring is the same as or different from other flavours in diverse tobacco products, particularly given the fact that menthol flavoured cigarette smokers account for one-third of all cigarette smokers in the USA, and menthol flavoured cigarette use has increased or remained stable, despite significant decreases in non-menthol cigarette use. ${ }^{6364}$

\section{CONCLUSIONS}

While further exploration of the impact that flavours have on tobacco use and perceptions are needed, existing evidence provides a rationale for banning non-menthol flavouring in most tobacco products to maximally protect youth from being enticed by flavours from tobacco use around the world. Further

\section{What this paper adds}

- The study highlights the key role of flavours in tobacco products in influencing perceptions and multiple tobacco use patterns about most tobacco products, particularly for adolescents; thus providing a rationale for banning non-menthol flavouring in most tobacco products.

- Further research on the impact of flavours, particularly given the increasing appeal and prevalence of flavoured tobacco products among young populations, should include the specification of the flavours' impact on tobacco use behaviours and perceptions, longitudinal research designs and reliability and validity of measures.

research examining flavoured tobacco products should include the specification of the flavours' impact on tobacco use behaviours and perceptions, particularly the impact of flavoured ecigarettes on adults cessation patterns with combustible tobacco, use standardised and validated measures and adopt longitudinal research designs to measure changes, especially behavioural outcomes, over time in relation to flavours.

Contributors L-LH and AOG conceptualised and designed the study. L-LH, CM, HMB and LMR conducted the data screening, extraction and analyses. L-LH led and oversaw the writing of the manuscript, with contributions from $C M, H M B, L M R$ and AR. AOG contributed to the manuscript by providing key information on the study context, suggestions about the analysis approach and interpretation of results. All authors read, provided comments and approved the final manuscript.

Funding Research reported in this publication was supported by grant number P50CA180907 from the National Cancer Institute and the FDA Center for Tobacco Products (CTP).

Disclaimer The content is solely the responsibility of the authors and does not necessarily represent the official views of the NIH or the Food and Drug Administration.

Competing interests None declared.

Provenance and peer review Not commissioned; externally peer reviewed.

Open Access This is an Open Access article distributed in accordance with the Creative Commons Attribution Non Commercial (CC BY-NC 4.0) license, which permits others to distribute, remix, adapt, build upon this work non-commercially, and license their derivative works on different terms, provided the original work is properly cited and the use is non-commercial. See: http://creativecommons.org/ licenses/by-nc/4.0/

\section{REFERENCES}

1 World Health Organization. Partial guidelines for implementation of Articles 9 and 10 of the WHO Framework Convention on Tobacco Control; Regulation of the contents of tobacco products and regulation of tobacco product disclosures. Adopted 2010, amended 2012. http://www.who.int/entity/fctc/guidelines/ Guideliness_Articles_9_10_rev_240613.pdf?ua=1

2 1256-111th HR. Family Smoking Prevention and Tobacco Control Act. 2009. http:/l www.govtrack.us/congress/bills/111/hr1256/text (accessed 15 Nov 2015).

3 Tobacco Control Legal Consortium. How Other Countries Regulate Flavored Tobacco Products. 2015. http://publichealthlawcenter.org/sites/default/files/resources/ International-Restrictions-on-Flavored-Tobacco-2015.pdf

4 Carpenter CM, Wayne GF, Pauly JL, et al. New cigarette brands with flavors that appeal to youth: tobacco marketing strategies. Health Aff (Millwood) 2005;24:1601-10.

5 Klein SM, Giovino GA, Barker DC, et al. Use of flavored cigarettes among older adolescent and adult smokers: United States, 2004-2005. Nicotine Tob Res 2008;10:1209-14.

6 Lewis MJ, Wackowski O. Dealing with an innovative industry: a look at flavored cigarettes promoted by mainstream brands. Am J Public Health 2006;96:244-51.

7 Delnevo CD, Wackowski OA, Giovenco DP, et al. Examining market trends in the United States smokeless tobacco use: 2005-2011. Tob Control 2014;23:107-12.

8 Food and Drug Administration. Deeming Tobacco Products to Be Subject to the Federal Food, Drug, and Cosmetic Act, as Amended by the Family Smoking 
Prevention and Tobacco Control Act; Regulations on the Sale and Distribution of Tobacco Products and Required Warning Statements for Tobacco Products. 2014. http://www.federalregister.gov/articles/2014/04/25/2014-09491/deemingtobacco-products-to-be-subjectto-the-federal-food-drug-and-cosmetic-act-asamended-by-the (accessed 15 Nov 2015).

9 Food and Drug Administration. TAB B 2014-850 Deeming Final Rule Redline Changes. 2016. https://www.regulations.gov/document? D=FDA-2014-N-0189-83193 (accessed 4 Oct 2016).

10 Zhu SH, Sun JY, Bonnevie E, et al. Four hundred and sixty brands of e-cigarettes and counting: implications for product regulation. Tob Control 2014;23(Suppl 3): iii3-9.

11 Corey CG, Ambrose BK, Apelberg BJ, et al. Flavored tobacco product use among middle and high school students—United States, 2014. MMWR Morb Mortal Wkly Rep 2015;64:1066-70.

12 Villanti $A C$, Richardson A, Vallone DM, et al. Flavored tobacco product use among U.S. young adults. Am J Prev Med 2013;44:388-91.

13 Minaker LM, Ahmed R, Hammond D, et al. Flavored tobacco use among Canadian students in grades 9 through 12: prevalence and patterns from the 2010-2011 youth smoking survey. Prev Chronic Dis 2014;11:E102.

14 Food and Drug Administration. Center for Tobacco Products, Food and Drug Administration: Research Priorities. 2012. http://www.fda.gov/downloads/ TobaccoProducts/NewsEvents/UCM293998. pdf (accessed 15 Nov 2015).

15 Parliament of Canada. An Act to amend the Tobacco Act. 2009. http://www.parl. gc.ca/HousePublications/Publication.aspx?Pub=Bill\&Doc $=C-32 \_4 \&$ Language $=$ \&Mode $=1 \&$ Parl $=40 \&$ Ses $=2 \&$ File $=4$

16 Tobacco Products Scientific Advisory Committee. Menthol Cigarettes and Public Health: Review of the Scientific Evidence and Recommendations. 2011. http://www. fda.gov/downloads/AdvisoryCommittees/CommitteesMeetingMaterials/ TobaccoProductsScientificAdvisoryCommittee/UCM269697.pdf

17 Food and Drug Administration. Preliminary scientific evaluation of the possible public health effects of menthol versus nonmenthol cigarettes. 2013. http://www. fda.gov/downloads/UCM361598.pdf (accessed 15 Nov 2015).

18 Feirman SP, Lock D, Cohen JE, et al. Flavored tobacco products in the United States: a systematic review assessing use and attitudes. Nicotine Tob Res 2016;18:739-49.

19 Sirriyeh R, Lawton R, Gardner P, et al. Reviewing studies with diverse designs: the development and evaluation of a new tool. J Eval Clin Pract 2012;18:746-52.

20 Yingst JM, Veldheer S, Hrabovsky S, et al. Factors associated with electronic cigarette users' device preferences and transition from first generation to advanced generation devices. Nicotine Tob Res 2015;17:1242-6.

21 Thrasher JF, Abad-Vivero EN, Moodie C, et al. Cigarette brands with flavour capsules in the filter: trends in use and brand perceptions among smokers in the USA, Mexico and Australia, 2012-2014. Tob Control 2016;25:275-83.

22 Amato MS, Boyle RG, Levy D. How to define e-cigarette prevalence? Finding clues in the use frequency distribution. Tob Control 2016;25:e24-9.

23 Berg CJ. Preferred flavors and reasons for e-cigarette use and discontinued use among never, current, and former smokers. Int J Public Health 2016;61:225-36.

24 Czoli CD, Goniewicz M, Islam T, et al. Consumer preferences for electronic cigarettes: results from a discrete choice experiment. Tob Control 2016;25:e30-6.

25 Etter JF. Electronic cigarettes: a survey of users. BMC Public Health 2010;10:231.

26 Farsalinos KE, Romagna G, Tsiapras D, et al. Impact of flavour variability on electronic cigarette use experience: an internet survey. Int I Environ Res Public Health 2013;10:7272-82.

27 Farsalinos KE, Romagna G, Tsiapras D, et al. Characteristics, perceived side effects and benefits of electronic cigarette use: a worldwide survey of more than 19,000 consumers. Int I Environ Res Public Health 2014;11:4356-73.

28 Ford A, MacKintosh AM, Bauld L, et al. Adolescents' responses to the promotion and flavouring of e-cigarettes. Int J Public Health 2016;61:215-24.

29 Kong G, Morean ME, Cavallo DA, et al. Reasons for electronic cigarette experimentation and discontinuation among adolescents and young adults. Nicotine Tob Res 2015;17:847-54.

30 Krishnan-Sarin S, Morean ME, Camenga DR, et al. E-cigarette use among high school and middle school adolescents in Connecticut. Nicotine Tob Res 2015;17:810-18

31 Nonnemaker J, Kim AE, Lee YO, et al. Quantifying how smokers value attributes of electronic cigarettes. Tob Control 2016;25:e37-43.

32 Pepper JK, Reiter PL, McRee AL, et al. Adolescent males' awareness of and willingness to try electronic cigarettes. J Adolesc Health 2013;52:144-50.

33 Pepper JK, Ribisl KM, Emery SL, et al. Reasons for starting and stopping electronic cigarette use. Int J Environ Res Public Health 2014;11:10345-61.

34 Shiffman S, Sembower MA, Pillitteri JL, et al. The impact of flavor descriptors on nonsmoking teens' and adult smokers' interest in electronic cigarettes. Nicotine Tob Res 2015;17:1255-62.

35 Shiplo S, Czoli CD, Hammond D. E-cigarette use in Canada: prevalence and patterns of use in a regulated market. BMJ Open 2015;5:e007971.
36 Tackett AP, Lechner WV, Meier E, et al. Biochemically verified smoking cessation and vaping beliefs among vape store customers. Addiction 2015;110:868-74.

37 Vasiljevic M, Petrescu DC, Marteau TM. Impact of advertisements promoting candy-like flavoured e-cigarettes on appeal of tobacco smoking among children: an experimental study. Tob Control 2016; Published Online First: 17 Jan 2016 doi:10.1136/tobaccocontrol-2015-052593

38 Agaku IT, Omaduvie UT, Filippidis FT, et al. Cigarette design and marketing features are associated with increased smoking susceptibility and perception of reduced harm among smokers in 27 EU countries. Tob Control 2015;24:e233-40.

39 Ashare RL, Hawk LW, Jr, Cummings KM, et al. Smoking expectancies for flavored and non-flavored cigarettes among college students. Addict Behav 2007:32:1252-61.

40 Doxey J, Hammond D. Deadly in pink: the impact of cigarette packaging among young women. Tob Control 2011;20:353-60.

41 Hammond D, Doxey J, Daniel S, et al. Impact of female-oriented cigarette packaging in the United States. Nicotine Tob Res 2011;13:579-88.

42 Hammond D, Daniel S, White CM. The effect of cigarette branding and plain packaging on female youth in the United Kingdom. J Adolesc Health 2013:52:151-7.

43 Kaleta D, Usidame B, Szosland-Faltyn A, et al. Use of flavoured cigarettes in Poland: data from the global adult tobacco survey (2009-2010). BMC Public Health 2014; 14:127.

44 Manning KC, Kelly KJ, Comello ML. Flavoured cigarettes, sensation seeking and adolescents' perceptions of cigarette brands. Tob Control 2009;18:459-65.

45 O'Connor RJ, Ashare RL, Cummings KM, et al. Comparing smoking behaviors and exposures from flavored and unflavored cigarettes. Addict Behav 2007;32:869-74.

46 White $\mathrm{CM}$, Hammond D, Thrasher JF, et al. The potential impact of plain packaging of cigarette products among Brazilian young women: an experimental study. BMC Public Health 2012;12:737.

47 Delnevo CD, Giovenco DP, Ambrose BK, et al. Preference for flavoured cigar brands among youth, young adults and adults in the USA. Tob Control 2015;24:389-94.

48 Leatherdale ST, Rios P, Elton-Marshall T, et al. Cigar, cigarillo, and little cigar use among Canadian youth: are we underestimating the magnitude of this problem? J Prim Prev 2011;32:161-70.

49 Yates EA, Dubray J, Schwartz R, et al. Patterns of cigarillo use among Canadian young adults in two urban settings. Can J Public Health 2014;105:e11-14.

50 Dani KK, Oswal K, Maudgal S, et al. Perception of young adults toward hookah use in Mumbai. Indian J Cancer 2015;52:694.

51 Salloum RG, Maziak W, Hammond D, et al. Eliciting preferences for waterpipe tobacco smoking using a discrete choice experiment: implications for product regulation. BMJ Open 2015;5:e009497.

52 Smith JR, Novotny TE, Edland SD, et al. Determinants of hookah use among high school students. Nicotine Tob Res 2011;13:565-72.

53 Adkison SE, Bansal-Travers M, Smith DM, et al. Impact of smokeless tobacco packaging on perceptions and beliefs among youth, young adults, and adults in the U.S: findings from an internet-based cross-sectional survey. Harm Reduct J 2014;11:2.

54 Oliver AJ, Jensen JA, Vogel RI, et al. Flavored and nonflavored smokeless tobacco products: rate, pattern of use, and effects. Nicotine Tob Res 2013;15:88-92.

55 Centers for Disease Control and Prevention (CDC). Bidi use among urban youth -Massachusetts, March-April 1999. MMWR Morb Mortal Wkly Rep 1999;48:796-9.

56 Ambrose BK, Day HR, Rostron B, et al. Flavored tobacco product use among US youth aged 12-17 years, 2013-2014. JAMA 2015;314:1871-3.

57 King BA, Tynan MA, Dube SR, et al. Flavored-little-cigar and flavored-cigarette use among U.S. middle and high school students. J Adolesc Health 2014;54:40-6.

58 Lee YO, Hebert CJ, Nonnemaker JM, et al. Youth tobacco product use in the United States. Pediatrics 2015;135:409-15.

59 Minaker LM, Shuh A, Nguyen N, et al. Cigarette smoking susceptibility among youth alternate tobacco product users: implications of flavoured tobacco from a national cross-sectional Canadian sample (YSS 2012/2013). BMJ Open 2015;5: e009549.

60 Farley SM, Johns M. New York City flavoured tobacco product sales ban evaluation. Tob Control Published Online First: 12 Feb 2016. doi:10.1136/tobaccocontrol-2015052418

61 Ontario Tobacco Research Unit. Prohibitions/restrictions on flavoured tobacco products—2013 monitoring update. 2013. http://otru.org/prohibitionsrestrictionsflavoured-tobacco-products-2013-monitoring-update/

62 Brown J, DeAtley T, Welding K, et al. Tobacco industry response to menthol cigarette bans in Alberta and Nova Scotia, Canada. Tob Control Published Online First: 19 Jul 2016. doi:10.1136/tobaccocontrol-2016-053099

63 Caraballo RS, Asman K. Epidemiology of menthol cigarette use in the United States. Tob Induc Dis 2011;9(Suppl 1):S1.

64 Giovino GA, Villanti AC, Mowery PD, et al. Differential trends in cigarette smoking in the USA: is menthol slowing progress? Tob Control 2015;24:28-37. 